Article

\title{
Inspection Robotic UGV Platform and the Procedure for an Acoustic Signal-Based Fault Detection in Belt Conveyor Idler
}

\author{
Hamid Shiri $\mathbb{D}^{\mathrm{D}}$, Jacek Wodecki *(D), Bartłomiej Ziętek (D) and Radosław Zimroz $(\mathbb{D}$ \\ Department of Mining, Faculty of Geoengineering, Mining and Geology, Wrocław University of Science and \\ Technology, 50-370 Wrocław, Poland; hamid.shiri@pwr.edu.pl (H.S.); bartlomiej.zietek@pwr.edu.pl (B.Z.); \\ radoslaw.zimroz@pwr.edu.pl (R.Z.) \\ * Correspondence: jacek.wodecki@pwr.edu.pl
}

\section{check for} updates

Citation: Shiri, H.; Wodecki, J.; Ziętek, B.; Zimroz, R. Inspection Robotic UGV Platform and the Procedure for an Acoustic Signal-Based Fault Detection in Belt Conveyor Idler. Energies 2021, 14 , 7646. https://doi.org/10.3390/ en14227646

Academic Editors: Daniela Marasová, Monika Hardygora and

Mirosław Bajda

Received: 19 October 2021

Accepted: 10 November 2021

Published: 16 November 2021

Publisher's Note: MDPI stays neutral with regard to jurisdictional claims in published maps and institutional affiliations.

Copyright: (c) 2021 by the authors. Licensee MDPI, Basel, Switzerland. This article is an open access article distributed under the terms and conditions of the Creative Commons Attribution (CC BY) license (https:// creativecommons.org/licenses/by/ $4.0 /)$

\begin{abstract}
Belt conveyors are commonly used for the transportation of bulk materials. The most characteristic design feature is the fact that thousands of idlers are supporting the moving belt. One of the critical elements of the idler is the rolling element bearing, which requires monitoring and diagnostics to prevent potential failure. Due to the number of idlers to be monitored, the size of the conveyor, and the risk of accident when dealing with rotating elements and moving belts, monitoring of all idlers (i.e., using vibration sensors) is impractical regarding scale and connectivity. Hence, an inspection robot is proposed to capture acoustic signals instead of vibrations commonly used in condition monitoring. Then, signal processing techniques are used for signal pre-processing and analysis to check the condition of the idler. It has been found that even if the damage signature is identifiable in the captured signal, it is hard to automatically detect the fault in some cases due to sound disturbances caused by contact of the belt joint and idler coating. Classical techniques based on impulsiveness may fail in such a case, moreover, they indicate damage even if idlers are in good condition. The application of the inspection robot can "replace" the classical measurement done by maintenance staff, which can improve the safety during the inspection. In this paper, the authors show that damage detection in bearings installed in belt conveyor idlers using acoustic signals is possible, even in the presence of a significant amount of background noise. Influence of the sound disturbance due to the belt joint can be minimized by appropriate signal processing methods.
\end{abstract}

Keywords: rolling element bearing; damage; idler; belt conveyor; sound; signal processing; inspection robot

\section{Introduction}

Belt conveyors are widely recognized as interesting objects for condition monitoring [1]. There are plenty of articles focused on the diagnostics of drive units (gearboxes, pulleys) using vibration analysis or infrared thermography [2-6] or temperature [7]. The conveyor belt has been defined as one of the most expensive component in conveyor, thus various NDT techniques (image analysis, laser scanning, magnetic field measurement) have been applied [8-13].

Researches on idlers were rather focused on rolling resistance, their energy consumption, load distribution, and failure analysis until now [14-18], however, some infrared thermography applications can be found in $[5,8,9]$, among others.

There are also other interesting research problems regarding conveyors, including destructive testing of steel-core belts, modeling of material stream behavior in a transfer point (between two conveyors), or detection of humans in harsh conditions (for the case when they are using conveyors as transport means for miners) [19-21]. However, these topics have no direct link to the predictive maintenance of such systems.

Rolling element bearings have been widely discussed in the literature [22-24]. In the case of conveyors, bearings are used in electric motors, gearboxes, pulleys, and, on a massive scale, in idlers. Mostly, vibration signals are used for fault detection $[22,23,25]$. 
Acoustic emission or just acoustic (sound) signals are rarely explored [26-31]. DelgadoArredondo at all [32], introduced methodology-based sound and vibration signals to fault detection on an induction motor. They used Ensemble Empirical Mode Decomposition to decompose the signal. Afterward, Gabor transform was utilized to calculate the spectral content of signals in the frequency domain. Their method could detect two broken rotor bars and mechanical unbalance defects. In [33] data driven methodology to detect fault in the combustion motor were introduced based on the Wavelet Packet Transform (WPT), Principle Component Analysis (PCA), and Bayesian optimization by using the acoustic signal.

A very interesting application of acoustic-based condition monitoring using a mobile phone has been proposed in $[26,27]$.

Bearings used in idlers are not very often discussed in the literature. The reason for that is likely the fact that vibration measurements are very difficult to perform for so many idlers. Therefore, it might be the best solution (or rather one of the most feasible solutions) to use a sound signal. Unfortunately, there are additional sources of noise and fault detection in such conditions that may be complicated to distinguish, especially if one can consider impulsive (what we will discuss later) disturbances in the acoustic signal.

An impulsive noise in signal processing procedures developed for local damage detection has been recognized as a critical challenge [34-48]. It is well known that faulty bearings produce a cyclic impulsive signal and the properties of the Signal of Interest depend on the bearing geometry, rotational speed, and fault size. There are two commonly used approaches for damage detection: searching for impulsiveness and periodicity. In the presence of impulsive disturbance, the first approach fails completely. To identify signatures in the spectrum with so-called fault frequency, one needs some preprocessing, which in practice is prefiltering used to select an informative frequency band. Again, prefiltering is mostly based on the search of impulsive behavior, which is hardly acceptable in this case. Moreover, even a classical envelope spectrum analysis or very advanced bi-frequency maps related to cyclostationary signal analysis may fail if the impulsive disturbance is really high [39-42,44,46].

As mentioned, due to the number of idlers located along the conveyor, there is a need to have a method for quick and automatic acoustic measurement and analysis. Thus, there are intensive works on inspection robots equipped with various sensors and data acquisition systems, including sound recording $[5,6,8,9,49-51]$. In the paper, we propose a combination of robotics inspection, acoustic data measurement, and finally signal processing for fault detection in idlers. The novel approach lies in proposing multidimensional data structure called spectral autocorrelation, which is an extension of the ordinary autocorrelation function calculated for the subsignals decomposed in the carrier frequency domain. The advantages of using such map are laid out at the final stage of result demonstration.

The acoustic signals acquired from mining machines are commonly mixed with highenergy environmental noise and interfaces from other neighboring devices. Furthermore, mining machines commonly work under time-varying speed, uncertain load conditions, and noncyclic impulsive noise that lead signals to have a complicated structure. Therefore, it is necessary to reduce this effect on the original signal by applying preprocessing methods. Adaptive mode decomposition approaches are well known and effective methods for dealing with such complex signals. They can identify the local properties of a signal with great confidence of separability. Adaptive mode decomposition approaches are well known and are effective methods for dealing with such complex signals. They can identify the local properties of a signal with great confidence of separability. Empirical mode decomposition (EMD) is a well-known adaptive mode decomposition method proposed to analyze non-stationary signals $[52,53]$. However, this method is suffering from mode mixing, endpoint effect, pseudo pulses, and other phenomena. Therefore, the local mean decomposition (LMD) was developed to determine the mode mixing problem in EMD. LMD utilized smoothed local means to evoke intrinsic modes from a signal instead of 
Hilbert transform used in the EMD algorithm [54-56]. Consequently, the information loss prompted by the Hilbert transform can be minimized.

The paper is structured as follows: after the introduction, the experiment is described and the most problematic aspects of the data processing are indicated. After that, the key aspects of the processing methods are described in theory. Finally, the results are presented with an indication of all intermediate steps and the conclusions are formed.

\section{Experiments and Data Description}

Idlers are rotating elements of the belt conveyor installed to support a moving belt. It consists of a shaft, two bearings, and coating. As the number of idlers is massive in practice (see Figure 1), a quick contactless method for bearing condition evaluation is required. The experiment discussed in this paper has been done on a real industrial object during regular operation. The conveyor itself is installed in a hall encapsulating the final process of the material extraction. In this hall, the final stage of belt conveyors is operated in order to discharge the material transported from the mining pit to the appropriate compartments that are storing the material temporarily. Hence, in this hall some sections of the conveyors are transporting the material to be dropped to the silos, and some of them perform a function of the final stage of conveyor series, where the belt is finalizing the loop and returning towards the excavation area. Until now, the inspection is done in a classical way, i.e., the expert is checking the condition using their own senses, i.e., sight and hearing (see Figure 2). However, the ultimate goal of the project is to replace such "human-based inspection" with a mobile inspection robot, as shown in (see Figure 3). In this figure one can see two belt conveyors installed in parallel. At the moment of the experiment, the right conveyor was stationary, while the left one was in operation and it was a subject of the inspection. While laser scanner was configured in a way to scan both of them, the headpiece containing other measurement devices, such as cameras, was directed towards the left conveyor.

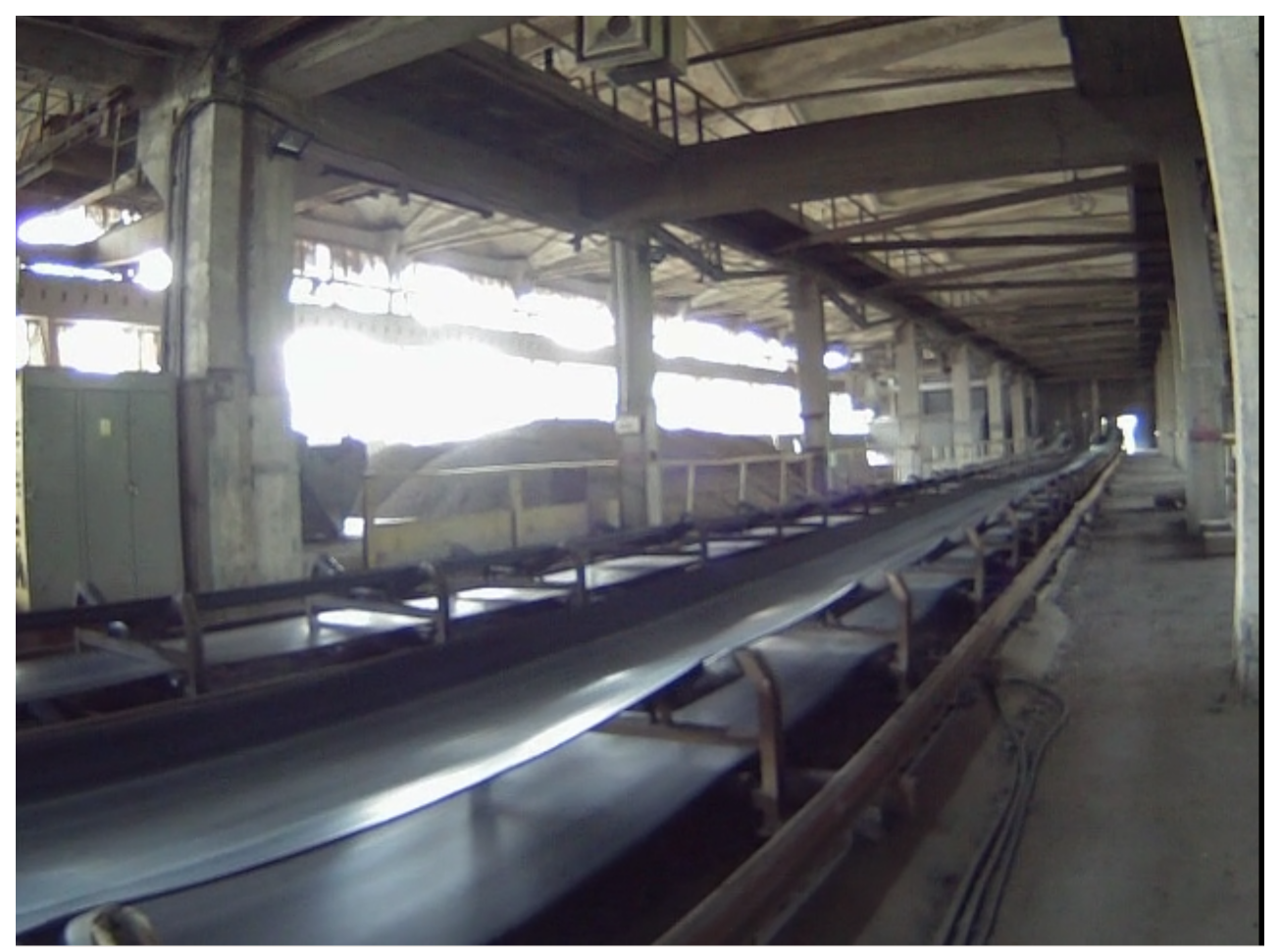

Figure 1. A general view of the belt conveyor. 


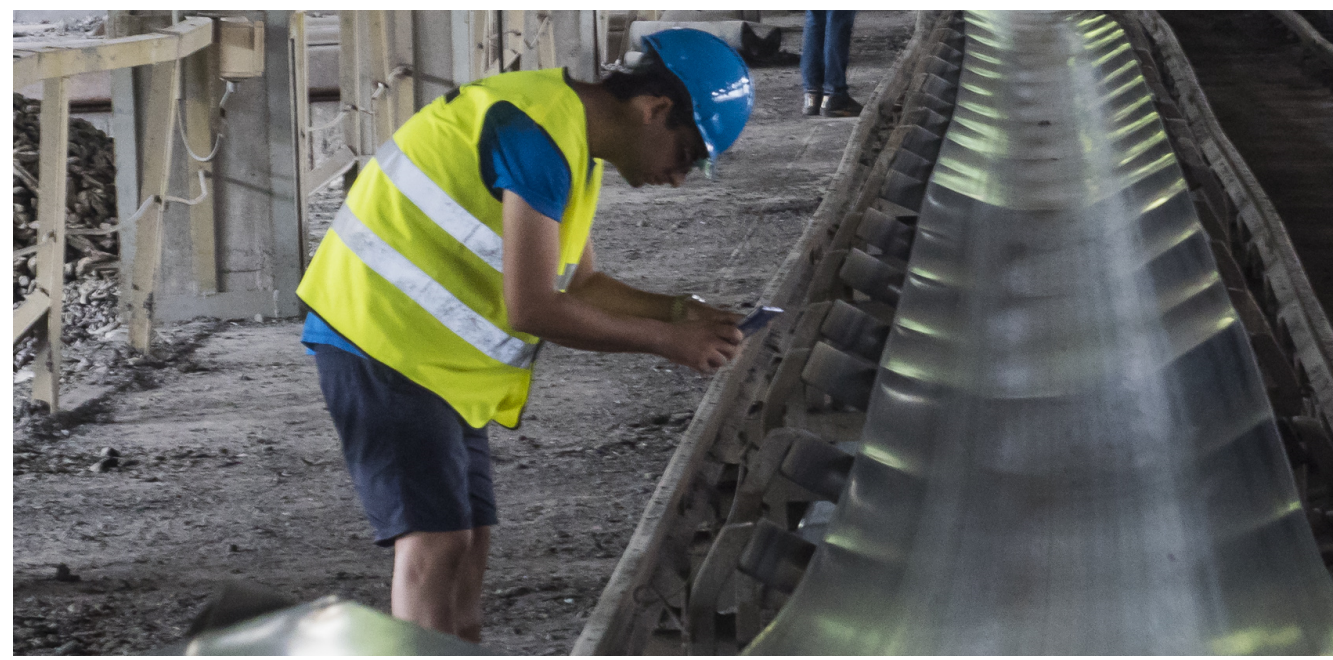

Figure 2. Traditional idler inspection.

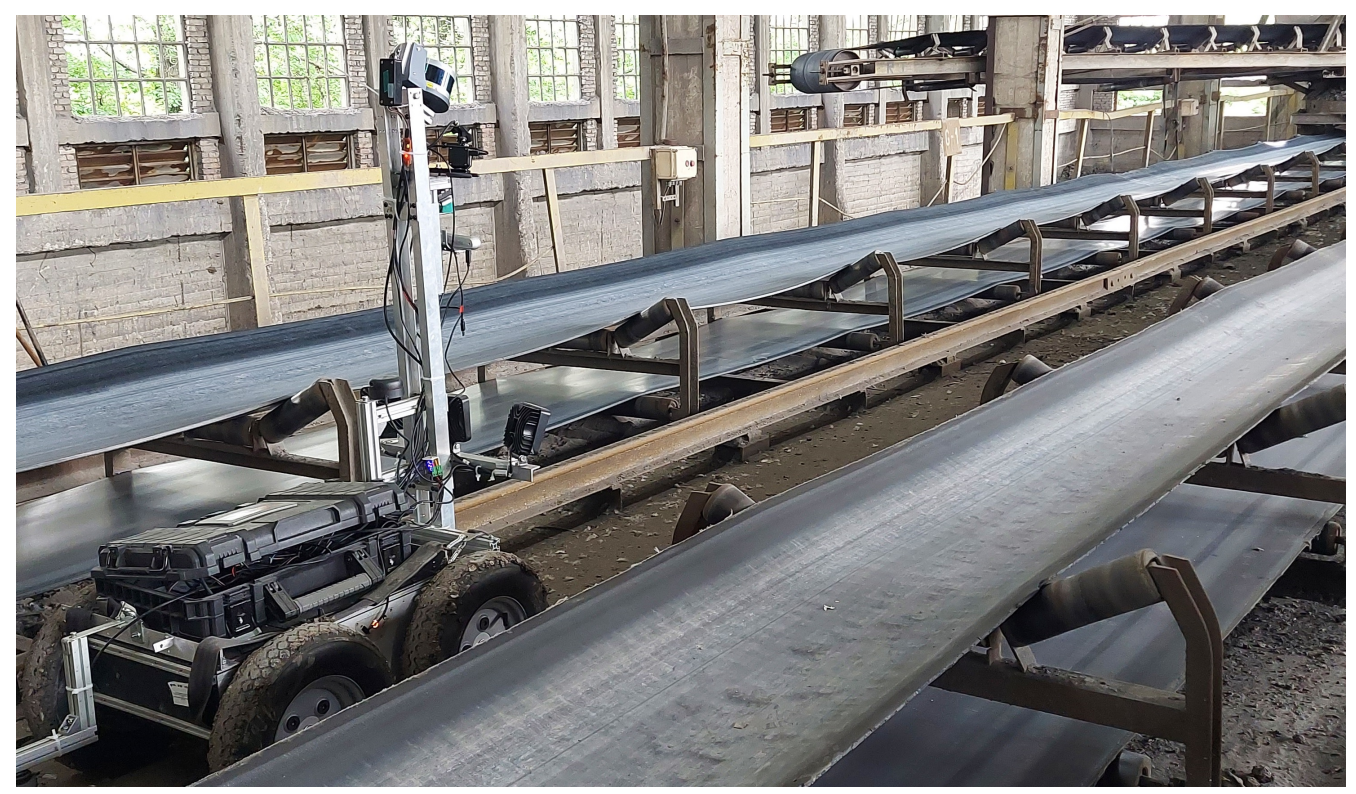

Figure 3. View of the robot during inspection.

During the experiments, a sound from each idler has been recorded, among others. The duration of the signal is c.a. $10 \mathrm{~s}$, with a sampling frequency of $48 \mathrm{kHz}$. Several interesting examples have been noticed, i.e., some idlers generated a cyclic impulsive signal, which is a clear signature of faulty bearings (see exemplary signals in Figure 4). However, it has been found that for some measurements, strong impulsive disturbances appeared (see exemplary signals in Figure 5). 

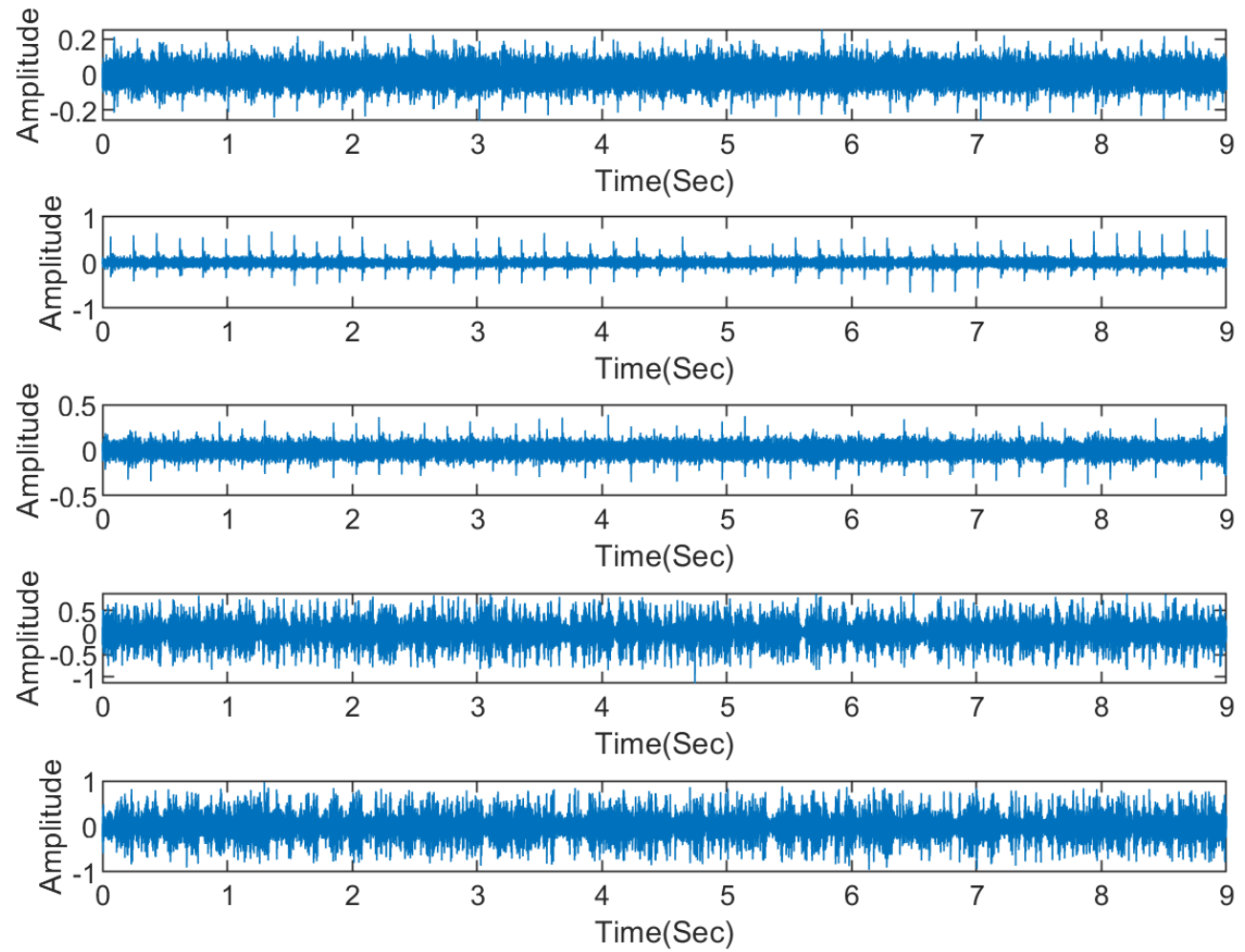

Figure 4. Selected examples of cyclic impulsive signals corresponding to faulty idlers.
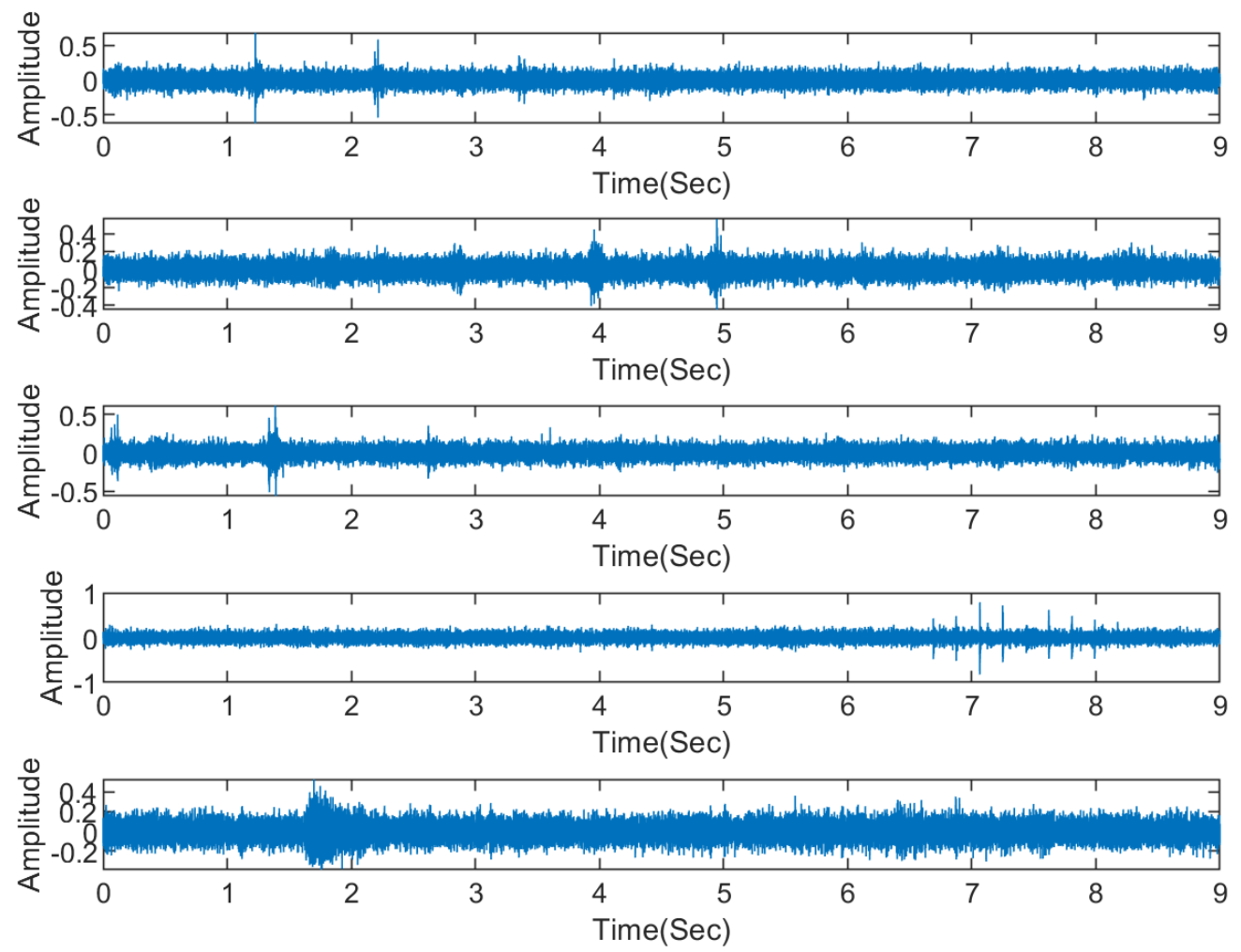

Figure 5. Selected examples of noncyclic impulsive signals corresponding to signal disturbances.

It may be concluded that several classes of signals can be distinguished in such a scenario, namely: non-impulsive signals (healthy case), cyclic impulsive signals (faulty case), noncyclic impulsive signals (or more precisely, impulsive signals that are not related 
to damage), and finally a mixture of cyclic and noncyclic signals. It is obvious that signals with different properties require more general, i.e., more advanced analysis. The two last cases are difficult to deal with, indeed. Such high energy impulse are represented in the frequency domain as wide-band excitation (see time-frequency representation of the exemplary signal in the Figure 6) and complicate the procedure of so-called informative frequency band detection. A similar effect can be observed in the time domain on the fourth subplot of Figure 5. The source of these noncyclic impulses (not related to damage) is a metal clip connecting two pieces of belt, which moves over the idlers and hits them with a force much stronger than a typical interaction between the belt and idler, see Figure 7 . In this context it is important to know that the belt is never a single consistent loop. It is manufactured as a linear strip, which is then installed as a loop by making a connection of the ends. There are many ways to make such connection, which depends on the type of belt used in a given conveyor (steel-core belt, textile belt, etc.) and on the preferred method of making a joint in a given application (sawtooth gluing, layered gluing, multilayer gluing, thermal vulcanization of several types, various types of mechanical connections, etc.).

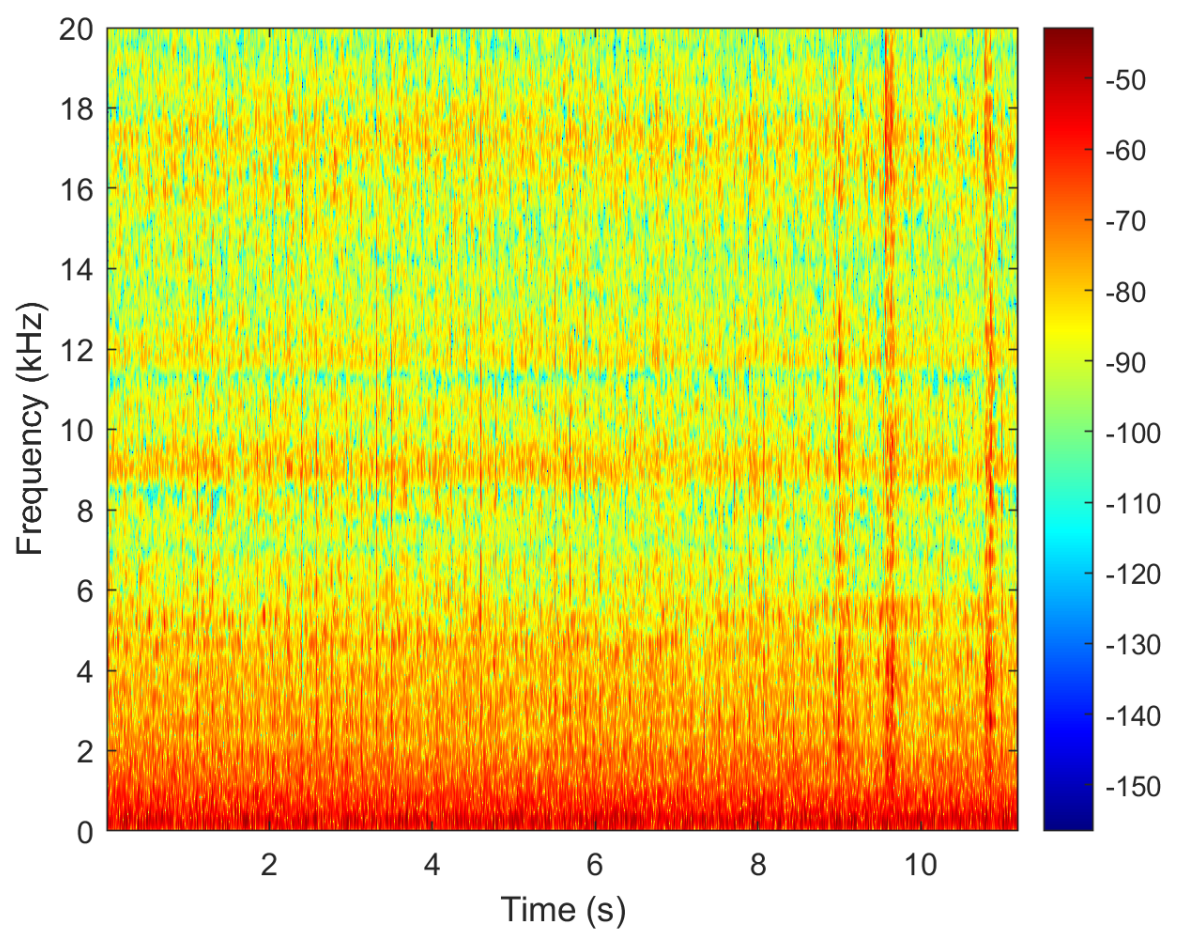

Figure 6. Time-frequency representation of the signal with impulsive disturbance.

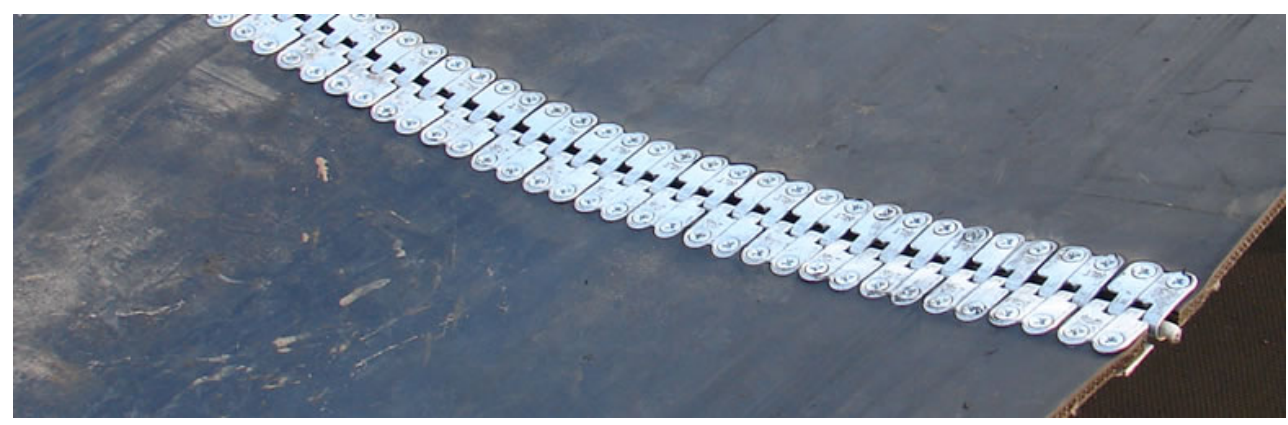

Figure 7. Belt joint using a metal clip.

\section{Methodology}

In this section, the key elements of the methodology are described. A general flowchart of the procedure is presented in Figure 8. 
Firstly, local mode decomposition (LMD) is used as a way to denoise the input signal in a data-driven manner. Then, a spectral autocorrelation (SAC) map is calculated for the denoised signal. It allows to observe cyclic behavior in the signal with respect to the carrier frequency spectrum. In the final stage of the result section, it is shown how the usage of such an approach provides better results than using ordinary autocorrelation function (ACF). In the next step, the SAC map is spatially denoised to further enhance its quality. Finally, such an enhanced map is integrated along the frequency dimension, which provides enhanced autocorrelation function (EACF), which operates with the same concept as enhanced envelope spectrum produced when cyclostationarity maps are integrated after enhancements. In the end, EACF allows to confirm the frequency of the idler rotation, which indicates the bearing fault.

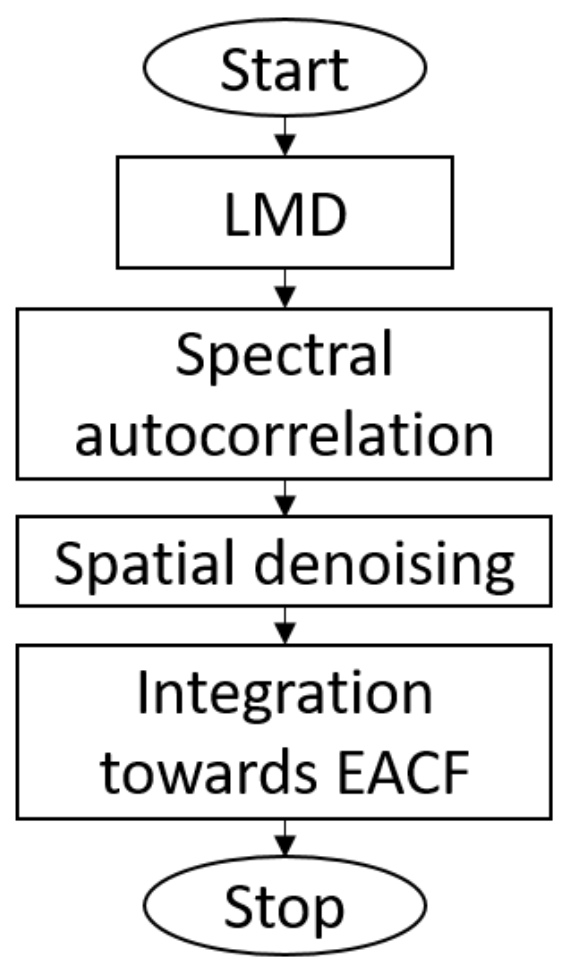

Figure 8. Flowchart of the procedure.

\subsection{Preprocessing}

LMD decomposes a complicated signal into a series of product functions (PFs) and a residue. Every $\mathrm{PF}$ is a mono-component that is produced from an envelope signal and a frequency modulated signal. In addition, A two-lever excursion algorithm is utilized to integrate the decomposition. The first step, a precise calculation of the $\mathrm{PF}$, is augmented through the inner cycle. Second, in the outer cycle, the decomposition process of the signal is performed based on iterations. For implementing LMD on the signal $x(t)$, eight steps are required.

Step 1: Extract all local extrema $n_{i}$ from the raw signal $x(t)$. Compute the local envelope estimate $a_{i}$ and local value $m_{i}$ of two consecutive extrema $n_{i}$ and $n_{(i+1)}$ by utilizing (1) and (2), respectively.

$$
\begin{aligned}
& m_{i}=\frac{n_{i+1}+n_{i}}{2} \\
& a_{i}=\frac{\left|n_{i+1}-n_{i}\right|}{2}
\end{aligned}
$$

Step 2: Make connections using direct lines between the local envelope estimate $a_{i}$ and local mean values $m_{i}$. 
Step 3: By applying the moving average method to smooth the local mean and envelope estimate, create the amplitude function $a_{11}(t)$ and local mean function $m_{11}(t)$.

Step 4: Calculate residue signal $h_{11}(t)$ by subtracting local mean function $m_{11}(t)$ from the raw signal.

$$
h_{11}(t)=x(t)-m_{11}(t)
$$

Afterward, calculate the frequency modulated signal $s_{11}(t)$ as follows

$$
s_{11}(t)=\frac{h_{11}(t)}{a_{11}(t)} .
$$

Step 5: To extract the envelope estimate $a_{12}(t)$ of $s_{11}(t)$, replicate steps $1-3$. If the envelope function $a_{11}(t)=1$, interrupt the process and select $s_{12}(t)$ as the first frequency modulated $(F M)$. Otherwise, select $s_{11}(t)$ instead of the raw signal and repeat Steps 1-4 $\mathrm{n}$ times until the envelope function $a_{1(n+1)}(t)$ of $s_{1 n}(t)$ convince $a_{1(n+1)}(t)$. The first iterative procedure can be defined as.

$$
\left\{\begin{array}{l}
h_{11}(t)=x(t)-m_{11}(t) \\
h_{12}(t)=s_{11}(t)-m_{12}(t) \\
\vdots \\
h_{11}(t)=s_{1(n-1)}(t)-m_{11}(t)
\end{array}\right.
$$

where

$$
\left\{\begin{array}{l}
s_{11}(t)=\frac{h_{11}(t)}{a_{11}(t)} \\
s_{12}(t)=\frac{h_{12}(t)}{a_{12}(t)} \\
\vdots \\
s_{1 n}(t)=\frac{h_{1 n}(t)}{a_{1 n}(t)}
\end{array}\right.
$$

Step 6: The corresponding instantaneous amplitude of the product function can be computed as follows.

$$
a_{1}(t)=a_{11}(t) a_{11}(t) \ldots a_{1 n}(t)=\prod_{q=1}^{n} a_{1 q}(t) .
$$

Step 7: Create the first product function $P F_{1}(t)$, utilizing.

$$
P F_{1}(t)=a_{1}(t) s_{1 n}(t) .
$$

In theory, $P F_{1}(t)$ consists of the main signal $x(t)$ oscillation information. The $I A$ of $P F_{1}(t)$ is $a_{1}(t)$, and the IF can be computed as.

$$
f_{1}(t)=\frac{1}{2 \pi} \frac{d\left[\arccos \left(s_{1 n}(t)\right)\right]}{d t} .
$$

Step 8: Calculate the residue signal $u_{1}(t)$. Consider $u_{1}(t)$ as a new signal and perform the described process $k$ times until $u_{k}(t)$ does not consist of oscillation. The second iterative process can be represented as follows.

$$
\begin{aligned}
& u_{1}(t)=x(t)-P F_{1}(t) \\
& \vdots \\
& u k(t)=u_{k-1}(t)-P F_{k}(t)
\end{aligned}
$$

Therefore, the primary signal can be reconstructed by utilizing it as follows

$$
x(t)=\sum_{p=1}^{k} P F_{k}(t)+u_{k}(t)
$$


where $k$ is shown the number of PFs and $u_{k}(t)$ is the residue signal.

The LMD methods flowchart is demonstrated in the Figure 9.

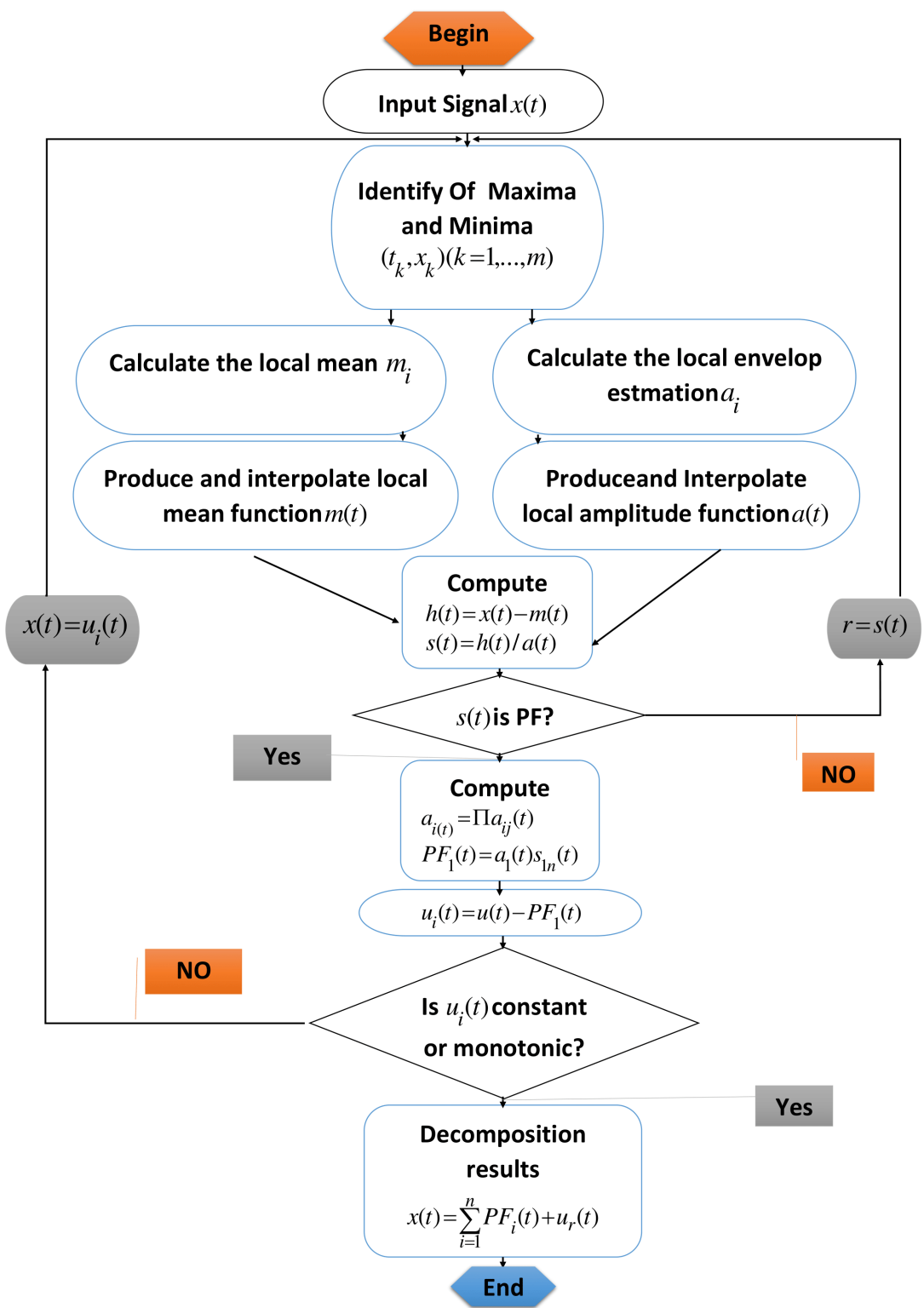

Figure 9. LMD flowchart.

\subsection{Spectral Autocorrelation}

To detect the cyclic component present in the signal, the authors propose the use of the spectral autocorrelation method. Firstly, the signal is decomposed in terms of its carrier frequency domain. In practice, this is realized by using a filter array FA of type-1 linear-phase FIR filters with Kaiser window, and filtering the signal using the FFT-based overlap-add method [57,58].

The number of filters in the array can be set as a parameter $n B$ and the filters have equal passband width with respect to $-3 \mathrm{~dB}$ cutoff frequencies with the width $d f=f s /(2 * n B)$. $-3 \mathrm{~dB}$ frequencies of the respective filters are also the crossover points between the neighboring filters. In practice, it means that the array consists of one lowpass filter for the frequency band $[0, d f]$, one highpass filter for the frequency band $[f s / 2-d f, f s / 2]$, and $n B-2$ bandpass filter for the remaining part of the Nyquist band. After filtering the input signal 
with this filter array, one can obtain an array of subsignals $Y^{n B \times T}$ where $T$ is the length of a time series, which is calculated as:

$$
Y_{i}=\operatorname{filter}\left(x, F A_{i}\right), \quad \text { for } \quad i \in 1: n B
$$

where the usage of operator $F A_{i}$ stands for filtering the same input signal $x$ with consecutive filters from the $F A$ array.

In the next step, for each of the obtained subsignals, the sample autocorrelation function $(\mathrm{ACF})$ is calculated. The autocorrelation itself measures the correlation between samples $y[t]$ and $y[t+k]$ of the signal $y$ where $k=0, \ldots, K$ and $K$ is a range of the calculated autocorrelation function.

According to [59] the autocorrelation for lag $k$ is defined as:

$$
A C F[k]=\frac{c[k]}{c[0]},
$$

where $c_{0}$ is the sample variance of a time series and

$$
c[k]=\frac{1}{T} \sum_{t=1}^{T-k}(y[t]-\bar{y})(y[t+k]-\bar{y}) .
$$

The full set of obtained ACFs is then arranged in the form of matrix $S A C^{n B \times K}$ according to the respective frequency bands of the filter that were used to obtain a given subsignal:

$$
S A C_{i}=A C F\left(y_{i}\right), \quad \text { for } \quad i \in 1: n B
$$

\subsection{Spatial Noise Modeling}

To enhance the quality of the SAC map, the authors decided to introduce a preconditioning step before the actual identification step, in order for noise levels across the map to be spatially modeled and subtracted from the data for each $\Delta f$.

The spatial context is created by the analysis of each carrier frequency bin $f=\left[f_{1}, \ldots, f_{n B}\right]$ along the lag dimension $\alpha=\left[\alpha_{1}, \ldots, \alpha_{n}\right]$. Each vector is modeled specifically to describe the energy of the noise within this frequency band.

Considering the described modeling conditions, each vector $S A C\left(f_{i}, \alpha\right)$ is modeled with a dual-term exponential function using the nonlinear least squares method. The obtained parameters $a_{i} \in A, b_{i} \in B, c_{i} \in C, d_{i} \in D$ (where $A, B, C, D$ are vectors of the parameters for the entire $f$ domain) of the exponential function are then allowed to obtain the noise model over the entire domain $\alpha$ for the given $f_{i}$. Such modeled noise components are arranged into a spatial noise map $N$, defined as follows:

$$
N(i, \alpha)=a_{i} \exp \left(b_{i} \alpha\right)+c_{i} \exp \left(d_{i} \alpha\right),
$$

which can be subtracted from the SAC map, effectively causing its denoising:

$$
S A C_{d}=S A C-N,
$$

where $S A C_{d}$ denotes the denoised SAC map.

\section{Results}

The raw input signal used in this paper is presented in Figure 10. In the first step, the signal has been denoised using the LMD method. The result of this operation is presented in Figure 11. One can notice that both the cyclic impulsive component as well as three noncyclic disturbances are more clearly visible. In general, the level of noise has been greatly reduced. To perform the analysis of cyclic behavior in the presence of large impacts originating from the mechanical joint passing over idlers, a spectral autocorrelation map has been calculated with the range parameter $K=1 \mathrm{~s}$. Authors found out that it is not 
needed to set a high resolution in the frequency domain and this representation works better with much lower resolutions than one would set, i.e., for a spectrogram. Hence, the parameter $n B=40$ turned out to be sufficient and the SAC map quality was satisfying, which can be seen in Figure 12.

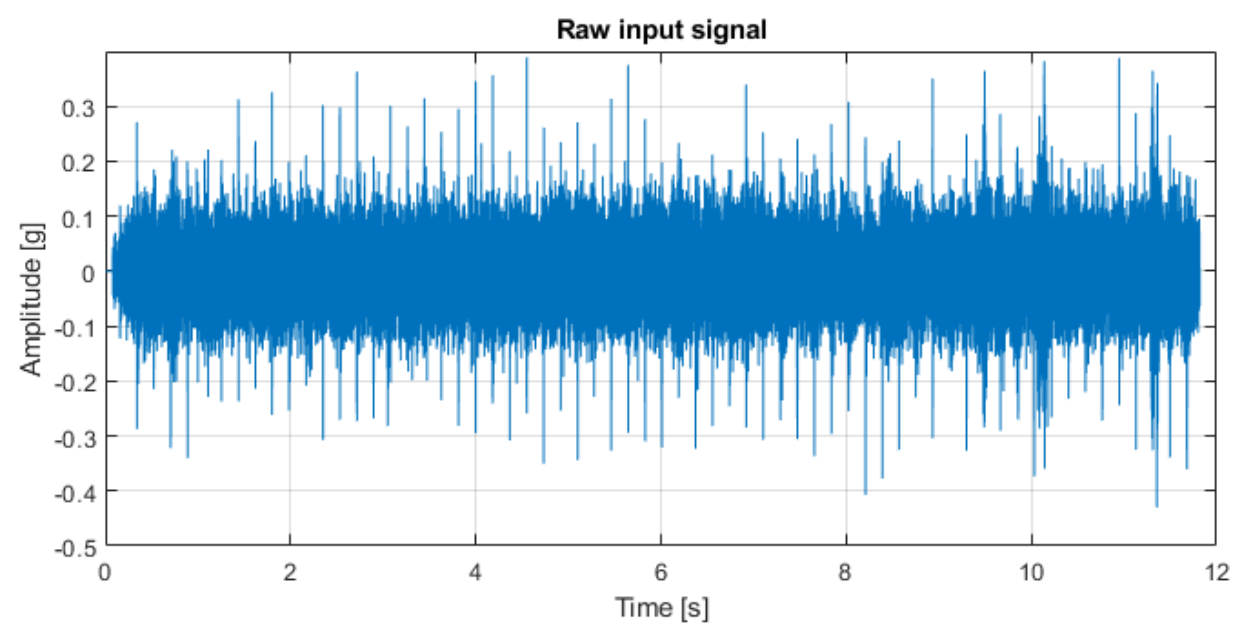

Figure 10. Raw input signal.

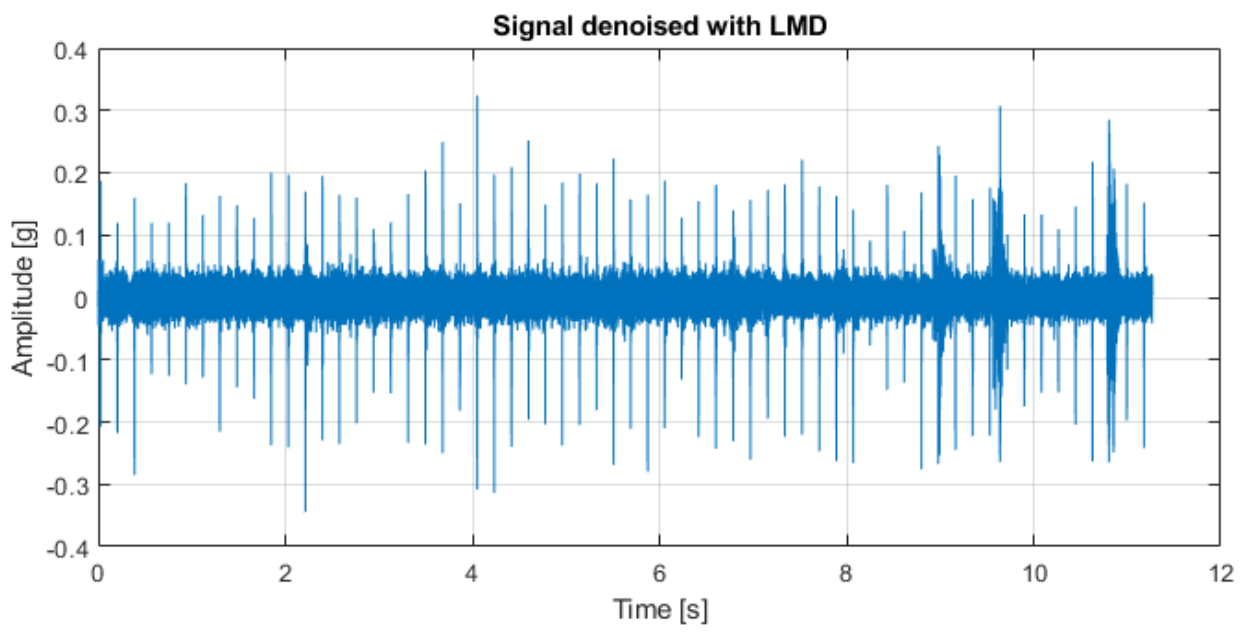

Figure 11. Signal denoised with LMD.

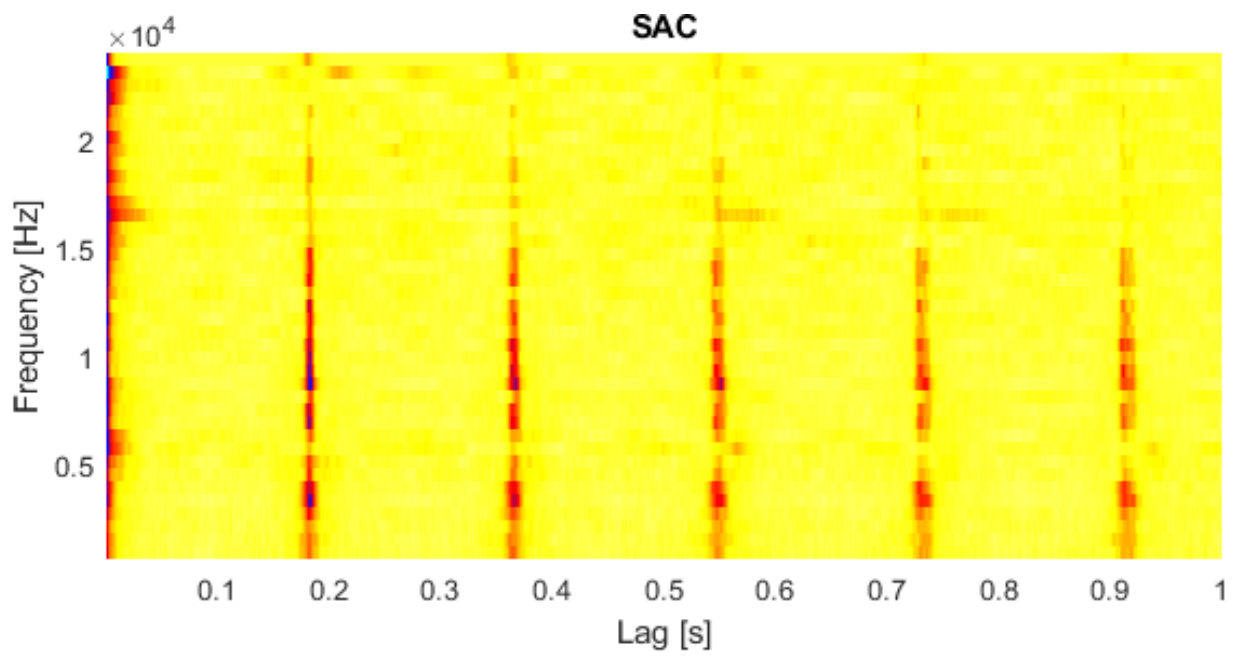

Figure 12. Spectral autocorrelation map. 
In the next step, the SAC map has been cleaned up by removing the background noise profile that contains high values around the lag values of 0 . To visualize this, Figure 13 presents the SAC map integrated along the frequency dimension, which displays the "equivalent autocorrelation function" with respect to the quality of the SAC map that we have at this point.

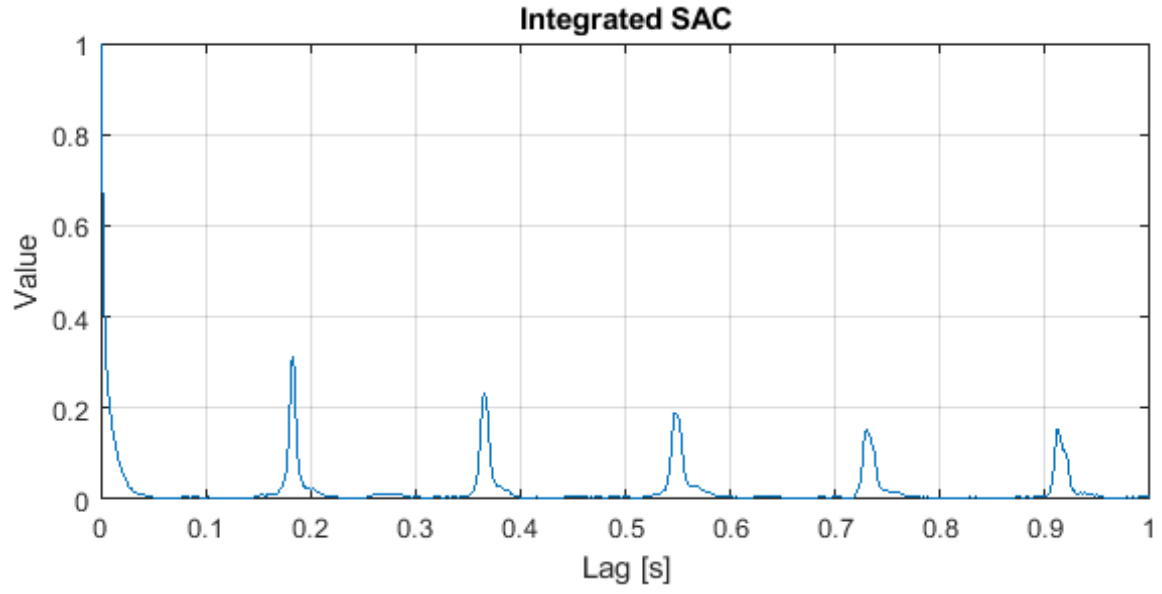

Figure 13. Integrated spectral autocorrelation map.

As expected, it is visible that the highest values are concentrated around zero lag, which interferes with thresholding or other simple detection methods. In order to remove this problem, a spatial noise model has been constructed (Figure 14) and removed from the map, which significantly improved the quality and highly simplified the subsequent steps (see Figure 15). One can notice that the vectors corresponding to the frequency bins are different from each other, which means that the unwanted background information is affecting different frequency bands with different strength. This indicates that it is reasonable to construct the model in the multidimensional domain instead of fitting a single model to the function in Figure 13. The model has been displayed in logarithmic scale to better emphasize the differences between the individual vectors.

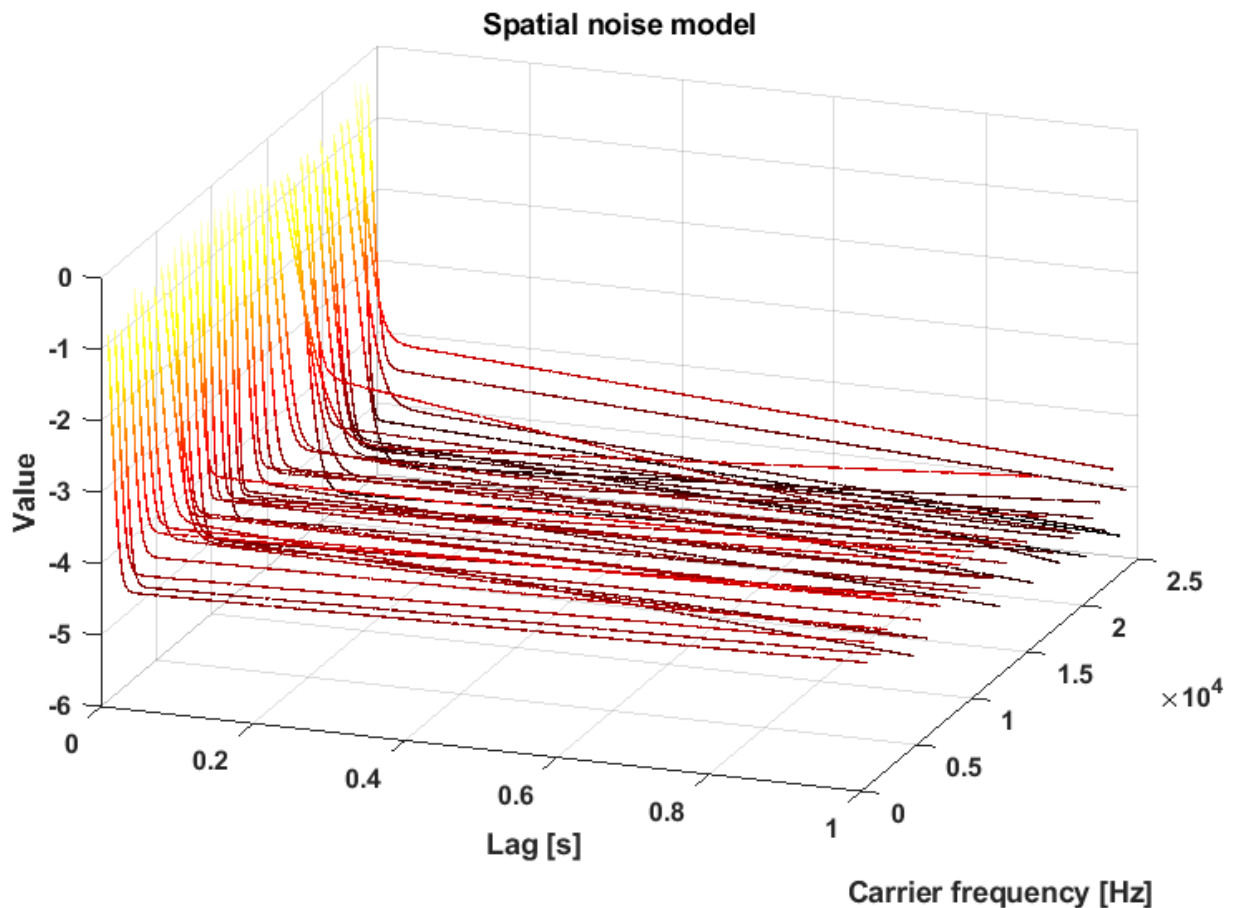

Figure 14. Spatial noise model. 


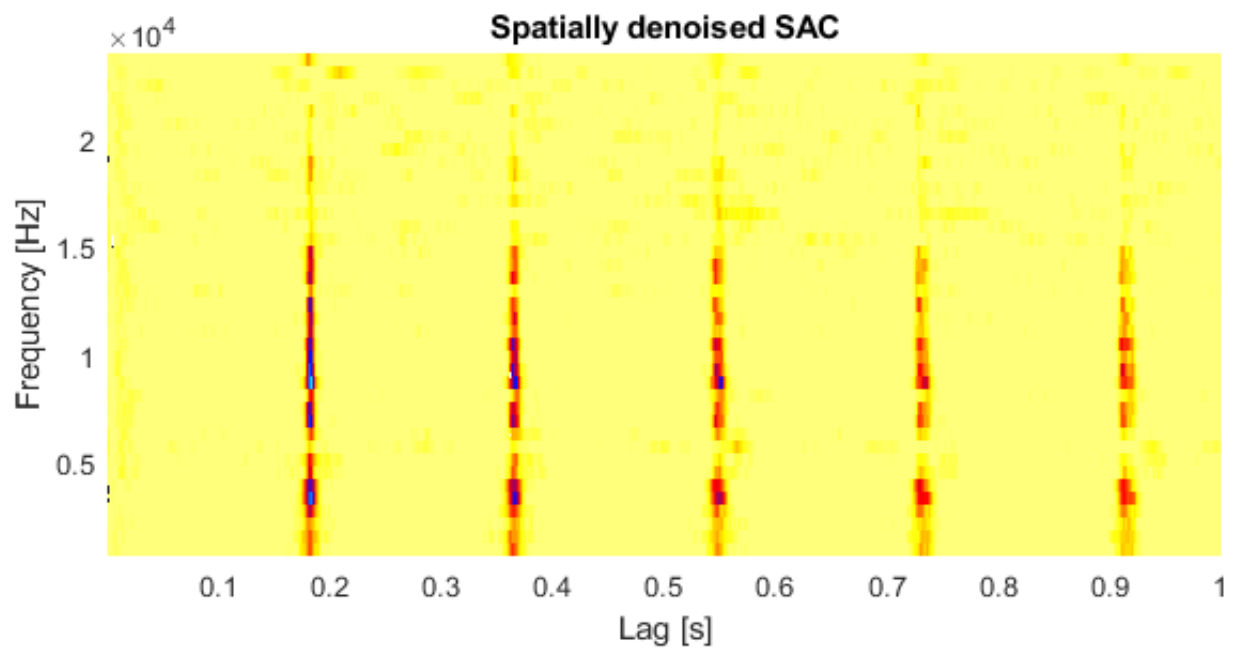

Figure 15. Spatially denoised spectral autocorrelation map.

Vectors of the denoised map have been averaged along the frequency axis, which forms a single enhanced autocorrelation function (EACF) (see Figure 16). The maximum value of this function (the value at the first peak) indicates the fundamental period of the cyclic component equal to $0.18 \mathrm{~s}$, which translates to the fault frequency of $5.46 \mathrm{~Hz}$.

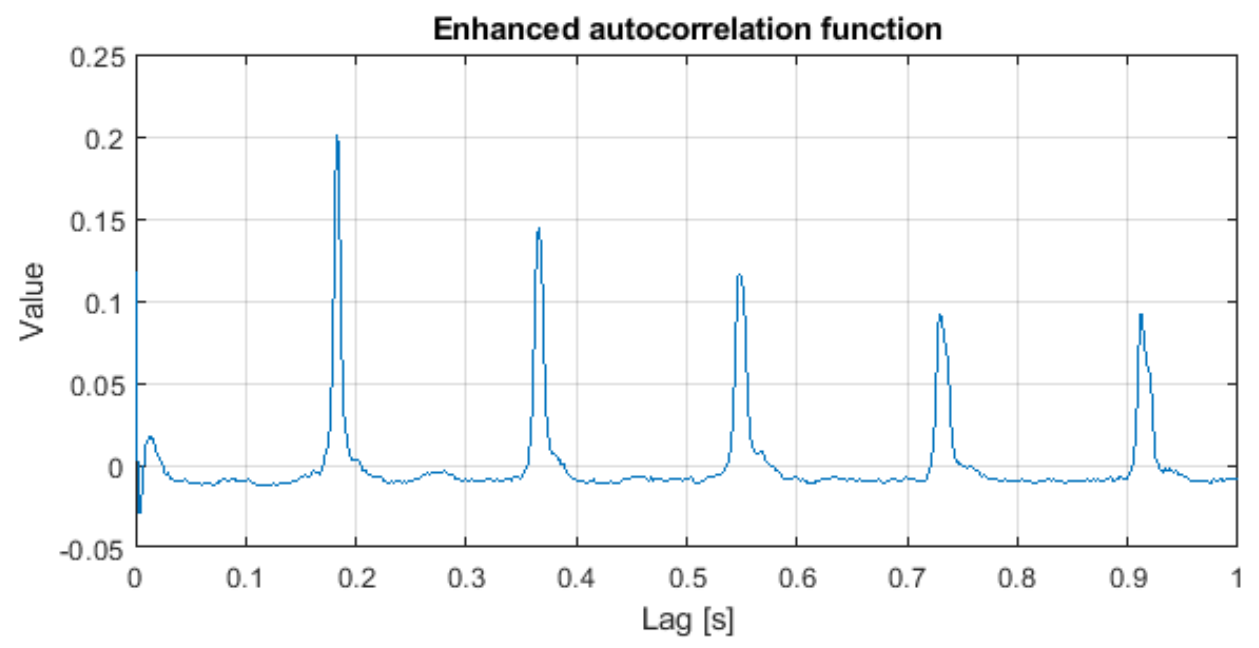

Figure 16. Enhanced autocorrelation function.

Figure 17 presents the classical autocorrelation function of the signal processed with LMD (which is the same signal that the analysis leading to EACF has been performed on). Comparison of the obtained EACF (see Figure 16) with classic ACF shows how much clarity one can achieve by choosing to perform multidimensional analysis, and how such an approach creates an opportunity to enhance the intermediate data representations leading to a better result. 


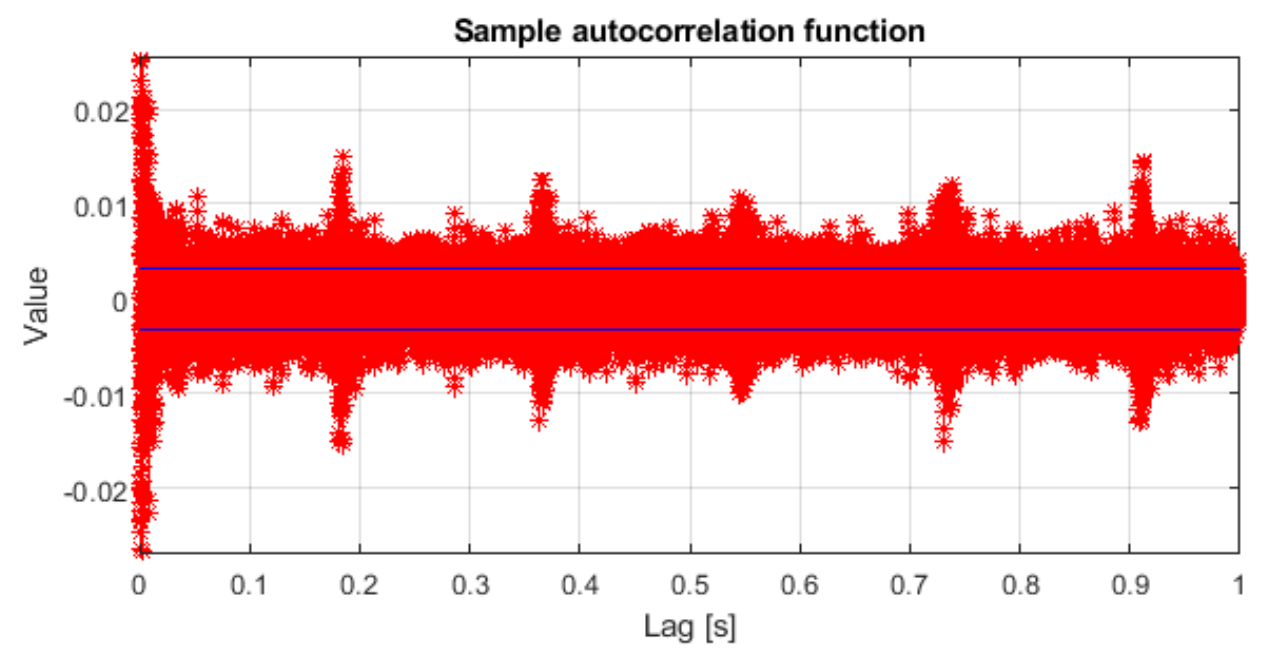

Figure 17. Classic sample autocorrelation function.

\section{Conclusions}

In this paper, the authors present a very promising method for damage detection in belt conveyor idlers. Based on the audio recording acquired by the mobile inspection robot, it was possible to automatically detect cyclic modulations indicating the mechanical fault of the idler. The method is especially useful because of its ability to ignore the information about random noncyclic wideband events such as mechanical connection of the belt. To achieve that, the spectral autocorrelation map was introduced as a base data structure for the analysis. Additionally, noise of the SAC map has been modeled individually with respect to the frequency domain and removed from the map. Finally, it is shown how the usage of SAC map leading to EACF provides better results than using ordinary autocorrelation function. In such scenarios, it is crucial to emphasize how simple it is to acquire data for such analysis. In our case, the mobile robot was used, but theoretically the audio signal could be recorded well enough with a simple voice recorder, or even a smartphone.

Author Contributions: Conceptualization, R.Z.; methodology, H.S. and J.W.; software, H.S., B.Z. and J.W.; validation, H.S., J.W. and R.Z.; formal analysis, J.W.; investigation, H.S. and B.Z.; resources, R.Z.; data curation, H.S. and B.Z.; writing—original draft preparation, H.S., B.Z. and J.W.; writing-review and editing, R.Z.; visualization, H.S. and J.W.; supervision, R.Z.; project administration, J.W.; funding acquisition, R.Z. All authors have read and agreed to the published version of the manuscript.

Funding: This activity has received funding from the European Institute of Innovation and Technology (EIT), a body of the European Union, under the Horizon 2020, the EU Framework Programme for Research and Innovation. This work is supported by EIT RawMaterials GmbH under Framework Partnership Agreement No. 19018 (AMICOS. Autonomous Monitoring and Control System for Mining Plants).

Institutional Review Board Statement: Not applicable.

Informed Consent Statement: Not applicable.

Data Availability Statement: Archived data sets cannot be accessed publicly according to the NDA agreement signed by the authors.

Acknowledgments: Supported by the Foundation for Polish Science (FNP).

Conflicts of Interest: The authors declare no conflict of interest. 


\section{References}

1. Obuchowski, J.; Wylomańska, A.; Zimroz, R. Recent developments in vibration based diagnostics of gear and bearings used in belt conveyors. Appl. Mech. Mater. 2014, 683, 171-176. [CrossRef]

2. Błazej, R.; Sawicki, M.; Kirjanów, A.; Kozłowski, T.; Konieczna, M. Automatic analysis of thermograms as a means for estimating technical of a gear system. Diagnostyka 2016, 17, 43-48.

3. Michalik, P.; Zajac, J. Use of thermovision for monitoring temperature conveyor belt of pipe conveyor. Appl. Mech. Mater. 2014, 683, 238-242. [CrossRef]

4. Szurgacz, D.; Zhironkin, S.; Vöth, S.; Pokorný, J.; Sam Spearing, A.; Cehlár, M.; Stempniak, M.; Sobik, L. Thermal imaging study to determine the operational condition of a conveyor belt drive system structure. Energies 2021, 14, 3258. [CrossRef]

5. Carvalho, R.; Nascimento, R.; D’angelo, T.; Delabrida, S.; Bianchi, A.; Oliveira, R.; Azpúrua, H.; Garcia, L. A UAV-based framework for semi-automated thermographic inspection of belt conveyors in the mining industry. Sensors 2020, 20, 2243. [CrossRef] [PubMed]

6. Yang, W.; Zhang, X.; Ma, H. An inspection robot using infrared thermography for belt conveyor. In Proceedings of the 2016 13 th International Conference on Ubiquitous Robots and Ambient Intelligence (URAI), Xi'an, China, 19-22 August 2016; pp. 400-404. [CrossRef]

7. Grzesiek, A.; Zimroz, R.; Śliwiński, P.; Gomolla, N.; Wyłomańska, A. Long term belt conveyor gearbox temperature data analysis-Statistical tests for anomaly detection. Meas. J. Int. Meas. Confed. 2020, 165, 108124. [CrossRef]

8. Szrek, J.; Wodecki, J.; Błazej, R.; Zimroz, R. An inspection robot for belt conveyor maintenance in underground mine-infrared thermography for overheated idlers detection. Appl. Sci. 2020, 10, 4984. [CrossRef]

9. Skoczylas, A.; Stefaniak, P.; Anufriiev, S.; Jachnik, B. Belt conveyors rollers diagnostics based on acoustic signal collected using autonomous legged inspection robot. Appl. Sci. 2021, 11, 2299. [CrossRef]

10. Kozłowski, T.; Wodecki, J.; Zimroz, R.; Błazej, R.; Hardygóra, M. A diagnostics of conveyor belt splices. Appl. Sci. 2020, 10, 6259. [CrossRef]

11. Trybała, P.; Blachowski, J.; Błażej, R.; Zimroz, R. Damage detection based on 3d point cloud data processing from laser scanning of conveyor belt surface. Remote Sens. 2021, 13, 55. [CrossRef]

12. Liu, X.; Pang, Y.; Lodewijks, G.; He, D. Experimental research on condition monitoring of belt conveyor idlers. Meas. J. Int. Meas. Confed. 2018, 127, 277-282. [CrossRef]

13. Liu, Y.; Miao, C.; Li, X.; Xu, G. Research on Deviation Detection of Belt Conveyor Based on Inspection Robot and Deep Learning. Complexity 2021, 2021. [CrossRef]

14. Kulinowski, P.; Kasza, P.; Zarzycki, J. Influence of design parameters of idler bearing units on the energy consumption of a belt conveyor. Sustainability 2021, 13, 437. [CrossRef]

15. Król, R.; Kisielewski, W. Research of loading carrying idlers used in belt conveyor-practical applications. Diagnostyka 2014, $15,67-74$.

16. Gładysiewicz, L.; Konieczna-Fuławka, M. Influence of idler set load distribution on belt rolling resistance. Arch. Min. Sci. 2019, 64, 251-259. [CrossRef]

17. Gładysiewicz, L.; Król, R.; Kisielewski, W. Measurements of loads on belt conveyor idlers operated in real conditions. Meas. J. Int. Meas. Confed. 2019, 134, 336-344. [CrossRef]

18. Vasić, M.; Stojanović, B.; Blagojević, M. Failure analysis of idler roller bearings in belt conveyors. Eng. Fail. Anal. 2020, 117, 104898. [CrossRef]

19. Wozniak, D.; Hardygóra, M Method for laboratory testing rubber penetration of steel cords in conveyor belts. Min. Sci. 2020, 27, 105-117. [CrossRef]

20. Doroszuk, B.; Król, R. Analysis of conveyor belt wear caused by material acceleration in transfer stations. Min. Sci. 2019, 26, 189-201. [CrossRef]

21. Uth, F.; Polnik, B.; Kurpiel, W.; Kriegsch, P.; Baltes, R.; Clausen, E. An innovative person detection system based on thermal imaging cameras dedicate for underground belt conveyors. Min. Sci. 2019, 26, 263-276. [CrossRef]

22. Rai, A.; Upadhyay, S. A review on signal processing techniques utilized in the fault diagnosis of rolling element bearings. Tribol. Int. 2016, 96, 289-306. [CrossRef]

23. Randall, R.; Antoni, J. Rolling element bearing diagnostics-A tutorial. Mech. Syst. Signal Process. 2011, 25, 485-520. [CrossRef]

24. Antoni, J.; Randall, R. The spectral kurtosis: Application to the vibratory surveillance and diagnostics of rotating machines. Mech. Syst. Signal Process. 2006, 20, 308-331. [CrossRef]

25. Roos, W.; Heyns, P. In-belt vibration monitoring of conveyor belt idler bearings by using wavelet package decomposition and artificial intelligence. Int. J. Min. Miner. Eng. 2021, 12, 48-66. [CrossRef]

26. Rzeszucinski, P.; Orman, M.; Pinto, C.; Tkaczyk, A.; Sulowicz, M. Bearing Health Diagnosed with a Mobile Phone: Acoustic Signal Measurements Can be Used to Test for Structural Faults in Motors. IEEE Ind. Appl. Mag. 2018, 24, 17-23. [CrossRef]

27. Orman, M.; Rzeszucinski, P.; Tkaczyk, A.; Krishnamoorthi, K.; Pinto, C.; Sulowicz, M. Bearing fault detection with the use of acoustic signals recorded by a hand-held mobile phone. In Proceedings of the 2015 International Conference on Condition Assessment Techniques in Electrical Systems (CATCON), Bangalore, India, 10-12 December 2015; pp. 252-256. [CrossRef] 
28. Pandey, S.; Amarnath, M. Applications of vibro-acoustic measurement and analysis in conjunction with tribological parameters to assess surface fatigue wear developed in the roller-bearing system. Proc. Inst. Mech. Eng. Part J J. Eng. Tribol. 2021, 235, $2034-2055$. [CrossRef]

29. Liu, X.; Pei, D.; Lodewijks, G.; Zhao, Z.; Mei, J. Acoustic signal based fault detection on belt conveyor idlers using machine learning. Adv. Powder Technol. 2020, 31, 2689-2698. [CrossRef]

30. Zhang, X.; Wan, S.; He, Y.; Wang, X.; Dou, L. Teager energy spectral kurtosis of wavelet packet transform and its application in locating the sound source of fault bearing of belt conveyor. Meas. J. Int. Meas. Confed. 2021, 173, 108367. [CrossRef]

31. Zhang, Y.; Martínez-García, M. Machine Hearing for Industrial Fault Diagnosis. In Proceedings of the 2020 IEEE 16 th International Conference on Automation Science and Engineering (CASE), Hong Kong, China, 20-21 August 2020; pp. 849-854.

32. Delgado-Arredondo, P.A.; Morinigo-Sotelo, D.; Osornio-Rios, R.A.; Avina-Cervantes, J.G.; Rostro-Gonzalez, H.; de Jesus RomeroTroncoso, R. Methodology for fault detection in induction motors via sound and vibration signals. Mech. Syst. Signal Process. 2017, 83, 568-589. [CrossRef]

33. Mathew, S.K.; Zhang, Y. Acoustic-based engine fault diagnosis using WPT, PCA and Bayesian optimization. Appl. Sci. 2020, 10, 6890. [CrossRef]

34. Wang, D. Spectral L2/L1 norm: A new perspective for spectral kurtosis for characterizing non-stationary signals. Mech. Syst. Signal Process. 2018, 104, 290-293. [CrossRef]

35. Barszcz, T.; Jabłoński, A. A novel method for the optimal band selection for vibration signal demodulation and comparison with the Kurtogram. Mech. Syst. Signal Process. 2011, 25, 431-451. [CrossRef]

36. Zhao, X.; Qin, Y.; He, C.; Jia, L.; Kou, L. Rolling element bearing fault diagnosis under impulsive noise environment based on cyclic correntropy spectrum. Entropy 2019, 21, 50. [CrossRef] [PubMed]

37. Żak, G.; Wyłomańska, A.; Zimroz, R. Periodically impulsive behavior detection in noisy observation based on generalized fractional order dependency map. Appl. Acoust. 2019, 144, 31-39. [CrossRef]

38. Nowicki, J.; Hebda-Sobkowicz, J.; Zimroz, R.; Wyłomańska, A. Dependency measures for the diagnosis of local faults in application to the heavy-tailed vibration signal. Appl. Acoust. 2021, 178, 107974. [CrossRef]

39. Wodecki, J.; Michalak, A.; Zimroz, R. Local damage detection based on vibration data analysis in the presence of Gaussian and heavy-tailed impulsive noise. Meas. J. Int. Meas. Confed. 2021, 169, 108400. [CrossRef]

40. Hebda-Sobkowicz, J.; Zimroz, R.; Wyłomańska, A. Selection of the Informative Frequency Band in a Bearing Fault Diagnosis in the Presence of Non-Gaussian Noise-Comparison of Recently Developed Methods. Appl. Sci. 2020, 10, 2657. [CrossRef]

41. Hebda-Sobkowicz, J.; Zimroz, R.; Pitera, M.; Wyłomańska, A. Informative frequency band selection in the presence of nonGaussian noise-a novel approach based on the conditional variance statistic with application to bearing fault diagnosis. Mech. Syst. Signal Process. 2020, 145, 106971. [CrossRef]

42. Wodecki, J.; Michalak, A.; Zimroz, R.; Barszcz, T.; Wyłomańska, A. Impulsive source separation using combination of Nonnegative Matrix Factorization of bi-frequency map, spatial denoising and Monte Carlo simulation. Mech. Syst. Signal Process. 2019, 127, 89-101. [CrossRef]

43. Schmidt, S.; Zimroz, R.; Chaari, F.; Heyns, P.S.; Haddar, M. A simple condition monitoring method for gearboxes operating in impulsive environments. Sensors 2020, 20, 2115. [CrossRef]

44. Kruczek, P.; Zimroz, R.; Antoni, J.; Wyłomańska, A. Generalized spectral coherence for cyclostationary signals with alpha-stable distribution. Mech. Syst. Signal Process. 2021, 159, 107737. [CrossRef]

45. Borghesani, P.; Antoni, J. CS2 analysis in presence of non-Gaussian background noise-Effect on traditional estimators and resilience of log-envelope indicators. Mech. Syst. Signal Process. 2017, 90, 378-398. [CrossRef]

46. Wodecki, J.; Michalak, A.; Wyłomańska, A.; Zimroz, R. Influence of non-Gaussian noise on the effectiveness of cyclostationary analysis - Simulations and real data analysis. Meas. J. Int. Meas. Confed. 2021, 171, 108814. [CrossRef]

47. Mauricio, A.; Qi, J.; Smith, W.A.; Sarazin, M.; Randall, R.B.; Janssens, K.; Gryllias, K. Bearing diagnostics under strong electromagnetic interference based on Integrated Spectral Coherence. Mech. Syst. Signal Process. 2020, 140, 106673. [CrossRef]

48. Yu, G.; Li, C.; Zhang, J. A new statistical modeling and detection method for rolling element bearing faults based on alpha-stable distribution. Mech. Syst. Signal Process. 2013, 41, 155-175. [CrossRef]

49. Cao, X.; Zhang, X.; Zhou, Z.; Fei, J.; Zhang, G.; Jiang, W. Research on the Monitoring System of Belt Conveyor Based on Suspension Inspection Robot. In Proceedings of the 2018 IEEE International Conference on Real-time Computing and Robotics (RCAR), Kandima, Maldives, 1-5 August 2018; pp. 657-661. [CrossRef]

50. Staab, H.; Botelho, E.; Lasko, D.; Shah, H.; Eakins, W.; Richter, U. A Robotic Vehicle System for Conveyor Inspection in Mining. In Proceedings of the 2019 IEEE International Conference on Mechatronics (ICM), Ilmenau, Germany, 18-20 March 2019; pp. 352-357. [CrossRef]

51. Garcia, G.; Rocha, F.; Torre, M.; Serrantola, W.; Lizarralde, F.; Franca, A.; Pessin, G.; Freitas, G. ROSI: A Novel Robotic Method for Belt Conveyor Structures Inspection; In Proceedings of the 2019 19th International Conference on Advanced Robotics (ICAR), Belo Horizonte, Brazil, 2-6 December 2019; pp. 326-331. [CrossRef]

52. Boudraa, A.O.; Cexus, J.C. EMD-based signal filtering. IEEE Trans. Instrum. Meas. 2007, 56, 2196-2202. [CrossRef]

53. Zheng, J.; Pan, H. Mean-optimized mode decomposition: An improved EMD approach for non-stationary signal processing. ISA Trans. 2020, 106, 392-401. [CrossRef] 
54. Yongbo, L.; Shubin, S.; Zhiliang, L.; Xihui, L. Review of local mean decomposition and its application in fault diagnosis of rotating machinery. J. Syst. Eng. Electron. 2019, 30,799-814.

55. Smith, J.S. The local mean decomposition and its application to EEG perception data. J. R. Soc. Interface 2005, 2, 443-454. [CrossRef]

56. Li, X.; Ma, J.; Wang, X.; Wu, J.; Li, Z. An improved local mean decomposition method based on improved composite interpolation envelope and its application in bearing fault feature extraction. ISA Trans. 2020, 97, 365-383. [CrossRef] [PubMed]

57. Oppenheim, A.V.; Schafer, R.W.; Buck, J.R. Discrete-Time Signal Processing; Pearson Education India: Upper Saddle River, NJ, USA, 1998; Volume 2.

58. Kaiser, J. Nonrecursive digital filter design using the I-sinh window function. In Proceedings of the 1974 IEEE International Symposium on Circuits \& Systems, San Francisco, CA, USA, 22-24 April 1974; pp. 20-23.

59. Box, G.E.; Jenkins, G.M.; Reinsel, G.C.; Ljung, G.M. Time Series Analysis: Forecasting and Control; John Wiley \& Sons: Hoboken, NJ, USA, 2015 